2020-07

\title{
Practice priorities for acute care nursing: A Delphi study
}

\section{Connell, CJ}

http://hdl.handle.net/10026.1/16024

\subsection{1/jocn.15284 \\ Journal of Clinical Nursing}

Wiley

All content in PEARL is protected by copyright law. Author manuscripts are made available in accordance with publisher policies. Please cite only the published version using the details provided on the item record or document. In the absence of an open licence (e.g. Creative Commons), permissions for further reuse of content should be sought from the publisher or author. 


\section{Practice Priorities for Acute Care Nursing: A Delphi study}

This is an accepted manuscript of an article published by Wiley in Journal of Clinical Nursing in April 2020 available at: https://doi.org/10.1111/jocn.15284

Connell C ${ }^{1}$,

Plummer $\mathrm{V}^{1}$,

Crawford K ${ }^{1}$,

Endacott $\mathrm{R}^{1,2}$,

Foley $\mathrm{P}^{1}$,

Griffiths $D^{1}$,

Innes $\mathrm{K}^{1}$,

Schwerdtle $\mathrm{P}^{1}$,

Walker $\mathrm{L}^{1}$,

Morphet $\mathrm{J}^{1}$

1. School of Nursing and Midwifery, Monash University, PO Box 527, Frankston, Vic. 3199,

Australia

2. School of Nursing and Midwifery, University of Plymouth, Plymouth, UK 


\section{Abstract}

Aims

To identify the enduring challenges in acute care nursing practice in Australian hospital wards based upon expert consensus.

\section{Background}

Healthcare is facing increasing demands that are negatively impacting upon the safety and quality of nursing care.

\section{Design}

Delphi Method

\section{Method}

A three round electronic Delphi method was used to collect and synthesise expert consensus opinion of 30 participants in Round One and Two of the survey, and 12 participants in Round Three. The study was carried out from July - December 2016. Reporting aligned with the STROBE guidelines.

\section{Results}

High patient acuity or complexity, as well as inadequate bedspace on wards, are 'very high' risks that occur 'often' and 'very often' respectively. The pressure to admit patients, delayed medical review and patient boarding are all 'high' risks that occur 'often'. Though only occurring 'sometimes', inadequate numbers and skill mix of staff, sub-optimal communication and early or inappropriate discharge all pose a 'very high' risk to patient care. 


\section{Conclusion}

The key priorities for nursing management and researchers should include sustainable system-wide frameworks, processes and models of care that address patient boarding, communication and discharge processes, job satisfaction, staffing numbers and expertise.

\section{Relevance to clinical practice}

This study provides a description of the challenges that face acute care nursing in the provision of safe and high-quality care.

What does this paper contribute to the wider global clinical community?

- This study describes the challenges related to patient care and communication throughout the admission and discharge processes, and during the in-patient stay that can negatively impact on the patient safety, as well as the quality and effectiveness of acute nursing care.

- Priorities for nursing practice should include sustainable system wide frameworks, processes and models of care that address the flow on affects (i.e. patient boarding, communication and discharge processes, job satisfaction, staffing numbers and expertise and failure to rescue) of existing and future demands to healthcare systems globally.

Keywords

Patient Safety, Quality Care, Acute Nursing Care, Adverse Events, Delphi study 


\section{Future directions for acute care nursing: A Delphi study}

\section{Introduction}

Globally, healthcare is facing increasing demands and inpatient admissions (Organisation for Economic Co-operation and Development, 2017). In Australia, the number of public hospital admissions has been steadily increasing at a rate of 3.0\% per year since 2009-10 (Australian Institute of Health and Welfare, 2016), similar to the United Kingdom rise of 33\% over a 10year period (NHS Digital 2017). In the face of these increasing demands and their potential to impact on the quality and completeness of safe nursing care (Jones, Hamilton, \& Murry, 2015), we sought to identify the challenges encountered in acute care nursing practice in Australian hospital wards, map these challenges against existing evidence and develop practice priorities based upon expert consensus. For the purposes of this study, a challenge is defined as adversity in clinical practice involving difficulty in delivering quality, patient centred care.

\section{Background}

Increasing admissions, overcrowding and a push to reduce length of stay can negatively impact indicators of safety and quality in hospitals, such as unplanned hospital readmissions, adverse events and death in low-mortality Diagnosis Related Groups (Alper, O'Malley, Greenwald, Aronson, \& Park, 2015; Kaukonen, Bailey, Suzuki, Pilcher, \& Bellomo, 2014). Unplanned hospital patient readmissions are associated with suboptimal quality of hospital care (Hasan et al., 2010), while adverse events have been linked to inadequate systems (de Vries, Ramrattan, Smorenburg, Gouma, \& Boermeester, 2008). An adverse event is any

unexpected and harmful experience that befalls a patient while being cared for in a healthcare system. It encompasses any emotional, physical acute or chronic harm that results 
in disability or death, unexpected transfers, admissions, readmissions or prolonged hospital stay (Baker et al., 2004; James, 2013). Preventable adverse events (PAEs) are the result of human and system limitations that affect between $20-30 \%$ of patients in hospital (Classen et al., 2011; Rutberg et al., 2014). The incidence of PAEs may be caused by mistakes or omissions in care, poor communication and diagnostic errors. These human and system failings may be compounded by increasing numbers and diversity of patients, limited staff resources and the complexity of delivering highly technical health care (Zegers et al., 2011). Though the literature surrounding PAEs is extensive, there is limited consensus expert opinion about the challenges facing nurses in ensuring safety and quality of care in hospitals. There is also evidence of significant financial burdens and increasing demands on access to healthcare by patients with a large range of chronic conditions and comorbidities (Sav et al., 2013). This influx has forced healthcare governance, including nursing management, to flex and change models of care to improve quality, safety and efficiency with little amelioration of resources to support these changes (Andreasson, Eriksson, \& Dellve, 2016; Asha \& Ajami, 2013). For example, to manage increasing demands on Emergency Department (ED) resources, in 2010 the Australian Government introduced the National Emergency Access Target (NEAT) (Baggoley et al., 2011). Similar to the British " 4 hour rule", the NEAT is a performance indicator that requires $90 \%$ of all ED episodes of care to be completed within four hours (Baggoley et al., 2011). While prolonged ED stays can be associated with increased patient morbidity and mortality (Richardson, 2006; Sprivulis, Da Silva, Jacobs, Frazer, \& Jelinek, 2006), there are concerns that admitting patients to the ward in less than four hours may not only compromise patient safety (Jones \& Schimanski, 2010; Mason, Weber, Coster, Freeman, \& Locker, 2012; Mortimore \& Cooper, 2007), but will exacerbate the demands on acute ward staff workload and availability (Crawford et al., 2014; Lipley \& Parish, 2008; Mortimore \& 
Cooper, 2007). In a broader scheme, the Australian National Safety and Quality Health Service Standards were developed (Australian Commission on Safety and Quality in Health Care), as a consistent approach designed to address highly prevalent adverse events such as medication errors, falls and failure to rescue (Australian Commission on Safety and Quality in Health Care, 2017).

Despite the commitment to deliver safe quality care and meet national performance indicators, $11 \%$ of patients have reported that nurses and doctors did not always spend enough time with them (Australian Institute of Health and Welfare, 2016). Data from a 2009 patient survey also suggests that cost, unacceptable waiting times and lack of available services were the main barriers to accessing services (Australian Bureau of Statistics, 2009). Similar indicators of substandard patient experiences exist internationally which warrants investigation to identify the contributing factors in acute care nursing (Bleustein et al., 2014; Bowling, Rowe, \& McKee, 2013; Care Quality Commission, 2013; Gan, Habib, Miller, White, \& Apfelbaum, 2014).

There have been limited attempts since 2001 to: i) identify the enduring challenges to achieving effective, safe and high quality nursing care, and ii) determine research priorities around these challenges for this priority area (Moreno-Casbas, Martín-Arribas, Orts-Cortés, \& Comet-Cortés, 2001; Schmidt, Montgomery, Bruene, \& Kenney, 1997).

\section{Aims}

The aims of the research were to identify enduring challenges in acute care nursing practice in Australian hospital wards, map these challenges against existing evidence and develop research priorities based upon expert consensus. 


\section{Design}

A three-round modified Delphi method (online data collection) was used to develop consensus regarding research priorities for acute care nursing with clinical nurses working at two Australian metropolitan public health services located to the south east of Melbourne, Victoria.

A Delphi method was used in this study, as a method for consensus-building (Crisp, Pelletier, Duffield, Adams, \& Nagy, 1997). The Delphi method is an iterative process using a number of surveys, in which researchers seek expert consensus to answer a question (Vernon, 2009). An electronic Delphi (e-Delphi) approach was used as it facilitated participant anonymity, and access to the same participants across multiple hospitals.

Reporting of the study findings from this study align with the STrengthening the Reporting of OBservational studies in Epidemiology (STROBE) guidelines (see Supplementary File 1).

\section{Setting}

The settings for this study were the acute medical and surgical wards of three public hospitals across two Victorian health services. Both provide services ranging from tertiary referral specialties to general acute medical and surgical care. Further details regarding each study site are at table 1.

INSERT TABLE 1 ABOUT HERE

Table 1

Demographics for the three study sites

\begin{tabular}{|l|l|c|c|c|}
\hline \multicolumn{2}{|c|}{} & Beds & $\begin{array}{c}\text { Annual } \\
\text { admissions }\end{array}$ & $\begin{array}{c}\text { Medical surgical } \\
\text { (approx.) }\end{array}$ \\
\hline Heath Service 1 & Hospital A & 640 & 70,000 & 10 \\
\cline { 2 - 5 } & Hospital B & 570 & 53,000 & 8 \\
\hline Health Service 2 & Hospital C & $?$ & 50,000 & 9 \\
\hline
\end{tabular}


1 Victorian Department of Health and Human Services (2017)

2 Australian Institute of Health and Welfare (2017)

\section{Ethics}

Ethical approval was obtained from each health service and Monash University Human Research Ethics Committee prior to data collection.

\section{Sample}

A purposive sampling method was used to recruit informed nurses with knowledge about the specific research subject. All registered nurses who worked in charge of medical or surgical acute wards, and responsible for patient management and flow, were considered to possess the knowledge and experience necessary to qualify them as experts in the clinical challenges facing nurses working in acute care hospitals in Victoria. All registered nurses working at either service in acute care wards, that take charge of the ward during a shift, were invited to take part in the study and therefore were included in an 'expert panel' for Round One of the Delphi.

\section{Data collection}

Emails were sent to the Nurse Unit Managers of each ward, inviting them to share the survey with nurses who worked in charge of each ward. Typically, this would be up to 15 staff per ward. Three rounds of survey were used. Email invitations to participate were distributed by the health care networks independent of the research team and QR coded flyers with links to the survey, survey information and participant eligibility were distributed on wards and general staff areas of the hospitals. Thirty registered nurses (health service $1, n=21$; health service $2, n=9$ ) were initially recruited and completed Round One of the Delphi process.

During Round One, participants were asked to list three things (up to a maximum of five) that make patient management challenging in an acute care ward: during admission; during the 
hospital stay; and on discharge. Each question response in Round One was independently coded by two members of the research team, consensus was reached between the two researchers, and then codes agreed upon by the whole research team. Responses were then collapsed for each question into lists of the challenges associated with each phase of the hospital process.

Round One participants were later invited to participate in Rounds Two and Three to iteratively build consensus expert opinion in keeping with the Delphi methodology (Heiko, 2012). In Round Two, participants were asked to rate i) the frequency which each clinical challenge (survey item) occurred, and ii) the potential risk to the patient on a five-point scale. In Round Three, participants were given the mean risk and frequency ratings of each survey item from Round Two, and asked to re-rate the risk and frequency with which each item occurred. The risk to patient care Likert type scale was anchored at one end with 'very low risk' (1) and at the other end with 'very high risk' (5). The frequency of occurrence Likert type scale ranged from 'very rarely' (1) to 'very often' (5). Free-text responses were also invited where any other items could be reported.

\section{Data analysis}

Content analysis was used to identify categories and themes from Round One. Quantitative responses in Round Two were analysed using mode to demonstrate which score was most frequently awarded. Mean and standard deviation (SD) were also used to analyse data and then results were returned to the participants for further refinement (Vernon 2009). Round Three data were also analysed using mode, mean, and standard deviation.

\section{Results}

Thirty participants completed the Round One survey. Respondents' roles included; Nurse Unit Managers (NUM, $n=6$ ), Associate Nurse Unit Managers (ANUM, $n=14$ ), Clinical Nurse 
Specialists (CNS, $n=5)$, Clinical Nurse Consultants (CNC, $n=1$ ) and Registered Nurses (RN, $n$ $=4)$. The detail of each response, and completeness of responding to each item varied from no response or short phrases, to paragraphs describing the challenges in detail. Thirty participants also responded to Round Two, and 12 participants completed Round Three. Participant attrition ( $N=18$ ) occurred despite initial clear information about expected participant time commitments and reminders about final round participation.

In Round One, participants identified challenges in care provision which fit into five broad domains: Patient Care; Communication; On Admission; During Patient Stay; and On Discharge. These challenges are presented under the five broad domains in order from those presenting the greatest risk to patient care and the frequency they occur.

\section{Patient Care}

Four items were reported as posing a 'high' to 'very high' risk to patient care. The number and skill mix of staffing, were a 'very high' risk which occurred 'sometimes'. Patient assessment delays related to patient boarding (wherein patients from one specialty unit are admitted to another specialty ward due to limited bed availability) occurred 'very often' and 'often', respectively (Table 1 ).

Place Table 1 about here

\section{Communication}

Suboptimal written and verbal communication were reported to present a 'high' risk to patients that occurred 'sometimes'. Participants indicated that an unclear plan of care was also a 'high' risk, but only occurred 'sometimes' (Table 2).

Place Table 2 about here 


\section{On Admission}

There were eight items on admission which were reported to pose a 'high' or 'very high' risk to patients, two of which were reported to occur 'often'. These included the pressure to admit patients from the emergency department within four hours of presentation and delays to medical review of patients. Finding additional staff when the acuity of patients in the ward had increased also posed a 'high' risk, but only occurred 'sometimes' (Table 3).

Place Table 3 about here

\section{During the Patient's Stay}

Challenges which contributed to increased risk during patient stay included inadequate bedspace on the ward for patients which was reported as a 'high' risk and occurred 'very often', and high patient acuity or complexity, which occurred 'often'. Other high-risk items identified were cancellation of surgery or lengthy delays, which occurred 'often', and failure to recognise or escalate care appropriately, which was reported to occur 'rarely' (Table 4).

Place Table 4 about here

\section{On Discharge}

The primary 'high' risks reported by participants related to discharge, were incomplete discharge summaries that occurred 'very often', inadequate or incohesive discharge planning which occurred 'sometimes' and the early or inappropriate discharge of patients due to insufficient bed availability, occurred 'rarely'. Other challenges related to discharge were reported to occur 'very often' included delays in receiving discharge medication but were perceived as a 'moderate' risk (Table 5).

Place Table 5 about here 


\section{Discussion}

The challenges facing acute care practice extend across the patients' progression from initial hospital admission, during admission, to patient discharge. The risk and frequency of these challenges range from those which are low risk and occur infrequently to those which pose a significant risk to the safety and quality of patient care and occur frequently (see figure 1).

\section{Place Figure 1 about here}

There was strong agreement that inadequate staffing numbers, range and types of staff expertise (skill mix) were considered a high risk. Despite the frequency of the risk, it has been shown elsewhere that nurses will leave the profession for a number of reasons that align with the concerns identified in our study (Cunich \& Whelan, 2010; Doiron, Hall, \& Jones, 2008; Thomas, Chaperon, \& Federation, 2013). Parker, Giles, and Higgins (2009) reported a range of first-hand reasons why nurses felt dissatisfied with their role and considered leaving. These included, but were not limited to, a lack of time to develop relationships with patients and colleagues, their own perception of being ineffective and trying to keep up with change. When deficits are identified around nurse numbers and skill mix the issue is not so much about the frequency of risk but, given its potential for harm, the obligation is to further investigate mitigating strategies to strengthen and support dynamic and flexible staffing architecture, staff satisfaction and retention (Parker et al., 2009).

The expert panel identified the issue of 'patient boarding' as both a high risk and one which happened very frequently. Patient boarding is when, due to limited bed availability, patients from a specialty unit are admitted to a different ward that may be unfamiliar and/or underresourced to deliver the specialised care required for the patient's individual needs. Again, this has been reported elsewhere (Parker et al., 2009) and is closely linked with attempts to manage increasing admissions and demands (Bornemann-Shepherd et al., 2015; Healy- 
Rodriguez et al., 2014). The impact of boarding upon the care of the patient includes delayed investigations, prolonged length of stay, PAE and suboptimal communication with and about the patient (Puvaneswaralingam \& Ross, 2016). Respondents in Round One of this study indicated that delays were experienced during the process of care due to "the timeframe in getting a patient reviewed by a doctor, particularly [boarders]" (participant 12B), and because boarding patients "were not a priority... and therefore, not seen till late in day" (participant 13A). As such, the research questions around patient boarding should not only address the broader mitigation of the practice, but also address adaptation that translates to safety strategies for patients who are separated from their home treating team.

Though the expert panel in this study identified the impact of poor communication as high risk, the issues of patient complexity, acuity and delayed in-patient reviews were problematic as they occurred often and posed a high risk to the patient. These and other effects, such as impact upon patient safety, also correlate with the strategies (e.g. boarding) for dealing with overcrowding and growing demands for access to hospital resources (Sri-On et al., 2014; Viccellio, Santora, Singer, Thode, \& Henry, 2009). Projected increases in population growth, urbanisation, an aging population; as well as an epidemiological transition from communicable to an increased burden of non-communicable diseases indicate that demands upon Australian hospitals will increase in the future (Armstrong, Gillespie, Leeder, Rubin, \& Russell, 2007; Commonwealth of Australia, 2010). Therefore, as we adjust to these increasing burdens, nursing is in the requisite position to better understand the challenges and further develop evidence-based practices for managing the flow on effects that are listed in this study.

Despite the evidence that prolonged ED stays can be associated with increased patient morbidity and mortality (Richardson, 2006; Sprivulis et al., 2006), there remains concern that 
admitting patients to the ward in less than four hours may compromise patient safety and create increased workloads for acute ward staff (Crawford et al., 2014). The expert panel from this study similarly reported the pressure to admit patients from the ED within four hours was a high risk to patient care that occurred often, impacted on the quality of handover "...leading to important information being missed" (participant 27B), as well as the effectiveness of communicating admission goals and care priorities. This was indicated by participants in Round One who acknowledged that admissions via the ED often have "no clear plan of management" (participant 13B) because patients were "not officially admitted by Med Reg" (participant 3A). Unpredictable patient admission rates and care needs also posed a challenge to flexing up staffing levels as bed occupancy and patient acuity increased. Dynamic changes in ward case-mix and occupancy such as these have been associated with failure to recognise and escalate the care of patients with physiological signs of deterioration (Park, Blegen, Spetz, Chapman, \& De Groot, 2012) and though identified as occurring rarely, 'failure to rescue' was considered to pose a very high risk to patient safety. This is consistent with overwhelming evidence that $15.8 \%$ of physiological deterioration is missed and $11.8 \%$ of patients who require escalation of their care, due to physiological deterioration, are mismanaged (Jacques, Harrison, McLaws, \& Kilborn, 2006). While the panel's expert consensus about the frequency of this high-risk issue may or may not be accurate, further research is indicated in this domain of the 'National Standards' (Australian Commission on Safety and Quality in Health Care 2017). There is likely no ideal time-frame for moving a patient requiring acute admission out of ED however, failing to adequately address ED overcrowding and reducing patient access to emergency care is clearly an inadequate and unsafe response to an inexorable problem. It is

\footnotetext{
${ }^{1}$ Medical Registrar
} 
therefore, incumbent upon nurse managers and researchers to develop and evaluate system approaches for managing the demand, addressing bottlenecks to flow as well as the volume, acuity and complexity of current and future patient populations.

The expert panel described a number of other high-risk occurrences that impacted upon the timely discharge of patients on a frequent basis. These occurrences included delays to receiving discharge medication or incomplete discharge summaries, whereas the inappropriate or "too early" discharge of a patient was an infrequent but high risk. The level of risk described is consistent with the literature, however the frequency of inappropriate/too early discharge was inconsistent with that which has been described elsewhere (Alper, O'Malley, Greenwald, Aronson, \& Park, 2015; Australian Institute of Health and Welfare, 2016; Jencks, Williams, \& Coleman, 2009). Regardless of frequency, the challenge of inappropriate/too early discharge presents an opportunity to potentially innovate the discharge process and represents an area requiring further research to mitigate or eliminate this challenge.

\section{Limitations}

There are a number of limitations to the research. Firstly, the research method's predisposition to participant attrition from round to round. This study initially recruited 30 participants to Round One which decreased to 12 participants by Round Three. However, participant attrition through progressive rounds is an inherent characteristic of the Delphi methodology and there is no agreement on the ideal sample size for a Delphi designed study (Williams \& Webb, 1994). Secondly, inadequate description of what constitutes an expert can be associated with Delphi technique. In this research, the experts were clinical nurses working in the setting, and were therefore, deemed to be able to provide insights and experiences to address the research aim. The use of an iterative process within the research team during 
data analysis decreased objectivity. Finally, results using the Delphi technique only present an expert opinion and do not provide a definitive answer to the research question (Powell 2003).

There is also a risk that the collective expert agreement is overly specific to an Australian context. We are satisfied that the panel's consensus opinion was suitably aligned with the broader international literature, and as such, reaffirms the value of the study to a wider setting. Self-selection bias may have influenced the findings. This occurs when those who elected to participate may not have the same characteristics or interpretations as those who chose not to participant. Finally, there is an important perspective that is missing from this manuscript. A more robust conclusion could be drawn if the design included an expert panel of patient representatives to identify the patient's experience of the issues impacting safety and quality to acute patient care.

\section{Conclusion}

This study identified a number of challenges that face acute care nursing and aligned the existing evidence that relates these challenges to in-patient safety and the quality of care received. There are fundamental challenges and key patient care priorities that have been revealed during the consensus-building process. Namely, there are significant issues related to patient care and communication throughout the admission and discharge processes, and during the in-patient stay that can negatively impact on the safety, quality and effectiveness of acute nursing care. No doubt, the issues identified would ideally benefit from global evidence based healthcare policy reform (Ham \& Murray, 2015). However, in lieu of this, nursing management and research collaborators must hold a pragmatic disposition that accepts current and anticipated economic reality and resource availability (Buchan, Twigg, Dussault, Duffield, \& Stone, 2015; Jones \& Sherwood, 2014). 
It was beyond the scope of this research to determine solutions to the identified issues, instead we suggest that nursing management and researchers develop an appetite for, and prioritise, the collaborative design and validation of strategies that will pragmatically address these enduring challenges. These should include sustainable system wide frameworks, processes and models of care that address the flow-on affects (i.e. patient boarding, communication and discharge processes, job satisfaction, staffing numbers and expertise and failure to rescue) of existing and future demands to the healthcare system. Principally, these priorities must translate to the sustained proliferation of evidence based, efficient and safe high-quality nursing care.

\section{Relevance to clinical practice}

This study provides healthcare administrators, nurse managers, researchers and policy makers with a description of the key challenges that face acute care nursing in the provision of safe and high-quality patient care. Our findings are reported in a way that clearly identifies these challenges, the level of risk posed to acute ward patients, and the frequency with which these risks occur. Therefore, the outcomes from this study can be used to prioritise, implement and evaluate acute care nursing practice and policy that enables sustainable system wide frameworks, processes and models of care which address the enduring and future demands to healthcare systems globally.

\section{Conflict of Interest}

No conflict of interest to declare 


\section{References}

Alper, E., O’Malley, T. A., Greenwald, J., Aronson, M. D., \& Park, L. (2017). Hospital discharge and readmission. Available at: www.uptodate.com/contents/hospital-discharge-andreadmission\#H1. uptodate. com/contents/hospital-discharge-and-readmission. Accessed August, 2019.

Andreasson, J., Eriksson, A., \& Dellve, L. (2016). Health care managers' views on and approaches to implementing models for improving care processes. Journal of Nursing Management, 24(2), 219-227.

Armstrong, B. K., Gillespie, J. A., Leeder, S. R., Rubin, G. L., \& Russell, L. M. (2007). Challenges in health and health care for Australia. Medical Journal of Australia, 187(9), 485.

Asha, S. E., \& Ajami, A. (2013). Improvement in emergency department length of stay using an early senior medical assessment and streaming model of care: a cohort study. Emergency Medicine Australasia, 25(5), 445-451.

Australian Bureau of Statistics. (2009). Health Services: Patient Experiences in Australia, 2009. Canberra, Australia. Retrieved from http://www.abs.gov.au/ausstats/abs@.nsf/Latestproducts/4839.0.55.001Main\%20F eatures12009?opendocument\&tabname=Summary\&prodno=4839.0.55.001\&issue $=$ 2009\&num $=\&$ view $=$

Australian Commission on Safety and Quality in Health Care. Australian Commission on Safety and Quality in Health Care (2010). National Consensus Statement: Essential Elements for Recognising and Responding to Clinical Deterioration. Sydney, ACSQHC. Sydney Retrieved from http://www.safetyandquality.gov.au/wpcontent/uploads/2012/01/national consensus statement.pdf

Australian Commission on Safety and Quality in Health Care. (2017). National Safety and Quality Health Service Standards. Sydney

Australian Institute of Health and Welfare. (2016). Australia's health 2016 (AUS 199). Retrieved from Canberra:

Australian Institute of Health and Welfare. (2017). MyHospitals. Retrieved from www.myhospitals.gov.au

Baggoley, C., Owler, B., Grigg, M., Wellington, H., Monaghan, M., \& Hartley-Jones, J. (2011). Expert panel review of elective surgery and emergency access targets under the national partnership agreement on improving public hospital services. Report to the Council of Australian Governments, 30.

Baker, G. R., Norton, P. G., Flintoft, V., Blais, R., Brown, A., Cox, J., . . Majumdar, S. R. (2004). The Canadian Adverse Events Study: the incidence of adverse events among hospital patients in Canada. Canadian Medical Association Journal, 170(11), 16781686.

Bleustein, C., Rothschild, D. B., Valen, A., Valatis, E., Schweitzer, L., \& Jones, R. (2014). Wait times, patient satisfaction scores, and the perception of care. The American Journal of Managed Care, 20(5), 393-400. 
Bornemann-Shepherd, M., Le-Lazar, J., Makic, M. B. F., DeVine, D., McDevitt, K., \& Paul, M. (2015). Caring for inpatient boarders in the emergency department: improving safety and patient and staff satisfaction. Journal of Emergency Nursing, 41(1), 23-29.

Bowling, A., Rowe, G., \& McKee, M. (2013). Patients' experiences of their healthcare in relation to their expectations and satisfaction: a population survey. Journal of the Royal Society of Medicine, 106(4), 143-149.

Buchan, J., Twigg, D., Dussault, G., Duffield, C., \& Stone, P. (2015). Policies to sustain the nursing workforce: an international perspective. International Nursing Review, 62(2), 162-170.

Care Quality Commission. (2013). Care Quality Commission Annual Report and Accounts 2012/13: Stationery Office.

Classen, D. C., Resar, R., Griffin, F., Federico, F., Frankel, T., Kimmel, N., . . . James, B. C. (2011). 'Global trigger tool'shows that adverse events in hospitals may be ten times greater than previously measured. Health Affairs, 30(4), 581-589.

Commonwealth of Australia. (2010). Intergenerational Report-Australia to 2050: future challenges. Commonwealth of Australia Canberra Retrieved from http://archive.treasury.gov.au/igr/igr2010/overview/pdf/igr 2010 overview.pdf

Crawford, K., Morphet, J., Jones, T., Innes, K., Griffiths, D., \& Williams, A. (2014). Initiatives to reduce overcrowding and access block in Australian emergency departments: $A$ literature review. Collegian, 21(4), 359-366.

Crisp, J., Pelletier, D., Duffield, C., Adams, A., \& Nagy, S. (1997). The Delphi method? Nursing Research, 46(2), 116-118. Retrieved from http://www.scopus.com/inward/record.url?eid=2-s2.0$\underline{0031093363 \& \text { partnerID }=40 \& m d 5=d 7383 e a 0676 e f d 39 e 4 e 34 d 2076 b 469 d 2}$

Cunich, M., \& Whelan, S. (2010). Nurse education and the retention of registered nurses in New South Wales. Economic Record, 86(274), 396-413.

de Vries, E. N., Ramrattan, M. A., Smorenburg, S. M., Gouma, D. J., \& Boermeester, M. A. (2008). The incidence and nature of in-hospital adverse events: a systematic review. Quality and Safety in Health Care, 17(3), 216-223.

Doiron, D., Hall, J., \& Jones, G. (2008). Is there a crisis in nursing retention in New South Wales? Australia and New Zealand Health Policy, 5(1), 19.

Gan, T. J., Habib, A. S., Miller, T. E., White, W., \& Apfelbaum, J. L. (2014). Incidence, patient satisfaction, and perceptions of post-surgical pain: results from a US national survey. Current Medical Research and Opinion, 30(1), 149-160.

Ham, C., \& Murray, R. (2015). Implementing the NHS five year forward view: aligning policies with the plan: King's Fund London.

Hasan, O., Meltzer, D. O., Shaykevich, S. A., Bell, C. M., Kaboli, P. J., Auerbach, A. D., .. . Schnipper, J. L. (2010). Hospital readmission in general medicine patients: a prediction model. Journal Of General Internal Medicine, 25(3), 211-219. 
Healy-Rodriguez, M. A., Freer, C., Pontiggia, L., Wilson, R., Metraux, S., \& Lord, L. (2014). Impact of a logistics management program on admitted patient boarders within an emergency department. Journal of Emergency Nursing, 40(2), 138-145.

Heiko, A. (2012). Consensus measurement in Delphi studies: review and implications for future quality assurance. Technological Forecasting and Social Change, 79(8), 15251536.

Jacques, T., Harrison, G. A., McLaws, M.-L., \& Kilborn, G. (2006). Signs of critical conditions and emergency responses (SOCCER): A model for predicting adverse events in the inpatient setting. Resuscitation, 69(2), 175-183. doi:10.1016/j.resuscitation.2005.08.015

James, J. T. (2013). A new, evidence-based estimate of patient harms associated with hospital care. Journal of patient safety, 9(3), 122-128.

Jencks, S. F., Williams, M. V., \& Coleman, E. A. (2009). Rehospitalizations among patients in the Medicare fee-for-service program. New England Journal of Medicine, 360(14), 1418-1428.

Jones, C. B., \& Sherwood, G. (2014). The globalization of the nursing workforce: Pulling the pieces together. Nursing outlook, 62(1), 59-63.

Jones, P., \& Schimanski, K. (2010). The four hour target to reduce emergency department 'waiting time': a systematic review of clinical outcomes. Emergency Medicine Australasia, 22(5), 391-398.

Jones, T., Hamilton, P., \& Murry, N. (2015). Unfinished nursing care, missed care, and implicitly rationed care: State of the science review. International Journal of Nursing Studies, 52(6), 1121-1137. doi:https://doi.org/10.1016/j.ijnurstu.2015.02.012

Lipley, N., \& Parish, C. (2008). Moving targets. Emergency Nurse, 16(2)(5).

Mason, S., Weber, E. J., Coster, J., Freeman, J., \& Locker, T. (2012). Time patients spend in the emergency department: England's 4-hour rule-a case of hitting the target but missing the point? Annals of Emergency Medicine, 59(5), 341-349.

Moreno-Casbas, T., Martín-Arribas, C., Orts-Cortés, I., \& Comet-Cortés, P. (2001). Identification of priorities for nursing research in Spain: a Delphi study. Journal of Advanced Nursing, 35(6), 857-863.

Mortimore, A., \& Cooper, S. (2007). The "4-hour target": emergency nurses' views. Emergency medicine journal, 24(6), 402-404.

Organisation for Economic Co-operation and Development. (2017). Health at a Glance 2017: OECD Indicators. Retrieved from http://dx.doi.org/10.1787/health glance-2017-en

Park, S. H., Blegen, M. A., Spetz, J., Chapman, S. A., \& De Groot, H. (2012). Patient turnover and the relationship between nurse staffing and patient outcomes. Research in Nursing \& Health, 35(3), 277-288.

Parker, V., Giles, M., \& Higgins, I. (2009). Challenges confronting clinicians in acute care. Journal of Nursing Management, 17(6), 667-678. doi:10.1111/j.13652834.2009.01009.x 
Powell, C (2003). The Delphi technique: myths and realities. Journal of Advanced Nursing, 41, 376-382.

Puvaneswaralingam, S., \& Ross, D. (2016). Improving the communication between teams managing boarded patients on a surgical specialty ward. BMJ quality improvement reports, 5(1), u209186. w203750.

Richardson, D. B. (2006). Increase in patient mortality at 10 days associated with emergency department overcrowding. Medical Journal of Australia, 184(5), 213.

Rutberg, H., Risberg, M. B., Sjödahl, R., Nordqvist, P., Valter, L., \& Nilsson, L. (2014). Characterisations of adverse events detected in a university hospital: a 4-year study using the Global Trigger Tool method. BMJ Open, 4(5), e004879.

Sav, A., Kendall, E., McMillan, S. S., Kelly, F., Whitty, J. A., King, M. A., \& Wheeler, A. J. (2013). 'You say treatment, I say hard work': treatment burden among people with chronic illness and their carers in Australia. Health \& Social Care in the Community, 21(6), 665-674.

Schmidt, K., Montgomery, L. A., Bruene, D., \& Kenney, M. (1997). Determining research priorities in pediatric nursing: a Delphi study. Journal of Pediatric Nursing, 12(4), 201207.

Sprivulis, P. C., Da Silva, J., Jacobs, I. G., Frazer, A. R., \& Jelinek, G. A. (2006). The association between hospital overcrowding and mortality among patients admitted via Western Australian emergency departments. Medical Journal of Australia, 184(5), 208.

Sri-On, J., Chang, Y., Curley, D. P., Camargo, C. A., Weissman, J. S., Singer, S. J., \& Liu, S. W. (2014). Boarding is associated with higher rates of medication delays and adverse events but fewer laboratory-related delays. The American Journal of Emergency Medicine, 32(9), 1033-1036.

Thomas, I., Chaperon, Y., \& Federation, A. N. (2013). Submission to the health workforce Australia consultation paper on nursing workforce retention and productivity. Australian Nursing Federation.

Vernon, W. (2009). The Delphi technique: A review. International Journal of Therapy and Rehabilitation, 16(2), 69-76.

Viccellio, A., Santora, C., Singer, A. J., Thode, H. C., \& Henry, M. C. (2009). The association between transfer of emergency department boarders to inpatient hallways and mortality: a 4-year experience. Annals of Emergency Medicine, 54(4), 487-491.

Victorian Department of Health and Human Services. (2017). Victorian Health Services Performance. Retrieved from http://performance.health.vic.gov.au/Home/Performance-Data-by-Hospital

Williams, P. L., \& Webb, C. (1994). The Delphi technique: a methodological discussion. Journal of Advanced Nursing, 19(1), 180-186.

Zegers, M., de Bruijne, M. C., de Keizer, B., Merten, H., Groenewegen, P. P., van der Wal, G., \& Wagner, C. (2011). The incidence, root-causes, and outcomes of adverse events in surgical units: implication for potential prevention strategies. Patient safety in surgery, 5(1), 13. 